\title{
ブルガリアの沖積漂砂鉱床に伴う特異な金製出土品
}

\author{
Unique finds of golden articles in alluvial placers in Bulgaria
}

\author{
Z.L. ツィンツォフ (Z.L. TSINTSOV)*
}

\begin{abstract}
Unique finds from placer deposits in the western Bulgaria are shown to discuss the interrelation among types of articles, the sites of gold-manufacturing, the placer deposits as the source of gold and the archeological significance of the discovery. The articles found in this area are characterized by both the gold and the precisely fine crafts. Most of them are identified archeologically with those at the same age of the Chalcolithic Necropolis near Varna in the eastern Bulgaria, where the metallic articles including copper and gold products were found in 1972 and have been considered to be of the oldest metal culture (before 4000 BC) in the world. The finding in the western Bulgaria are also valuable in following two facts that the sites of manufacturing gold-articles were specified to be very near to the gold-placer deposits and that the articles are comparable in various natures with those of the Varna Necropolis.
\end{abstract}

Keywords: Placer deposit, Golden article, Archeology, Metal culture, Bulgaria, Varna, Chalcolithic necropolis, Sperrylite

\section{I. バルカン半島地域における金漂砂鉱床}

人類社会の発展にとって金属の発見は決定的に重要な エポックであった。金属は天然資源の一つとして太古から 興味の対象であり，使用目的に応じて，人々はその諸性質 を様々に利用してきた。人と金属の関係は，密接かつ余り に永く, 金属の最初の発見や使用開始時期などは特定でき ないほどである (Pernicka, 1994)。金について言えば, それ がどこで最初に使用されたかは知られていないが，人類の 歴史に確実に影響を与えており，その歷史は文明の歴史そ のものであるともいえる。

古代ヨーロッパにおいて，幾つかの重要な金鉱床地帯が 知られている。それらの一つが，バルカン半島地域に存在 し,この地域の鉱床から採取されてきた金の量は, $1020 \mathrm{~m}^{3}$ に達するといわれている (Marfunin, 1987)。この地域の一 部をなすブルガリアの金漂砂鉱床も地質学, 鉱山学, 冶金 学, 考古学の専門家の強い興味の対象であった。この地域 の当時の鉱山師 (やまし) は, ほとんど直感により多くの 鉱山開発を行っているが，それらは比較的規模も大きく, 特に Kraishte 地域の含金漂砂鉱床に特に興味を示したよ うである。そこには古い掘り跡，「水ひ」された河川堆積物 の山, 給水用構築物などが見られる (Konyanov, 1953)。勿 論, 当時の鉱山開発も, これら漂砂鉱床の金の含有量, 粒 径, 形態等に依存した分布パターンにかなり規制されてい
る。古代の地質屋は, 調査方法や分析法方が不十分であり, 最も表層の試料を採取して探査を行っていたが，彼らの技 術力を示す好例は，例えば，現在の研究によれば，中央ブ ルガリアの交替変成岩中の金は特定の鉱物中に存在せず, 品位が $200 \mathrm{ppm}$ 程で均質に分布している (Tsintsov，未発 表デー夕)にもかかわらず，その鉱床を知っていた事など に見られる。鉱業的探査はいわゆる “rupi”すなわち，(ブ ルガリア語の)「表層掘り」により始められていた。金はブ ルガリアにおける漂砂鉱床の主要産物であるが, 長年の研 究にもかかわらずその全容は明らかになっていない。その 理由について Konyarov (1953) は，太古において既に採り 尽くされ，もはや鉱業的興味に欠けるからであると説明し ている。

近代になって漂砂鉱床の主たる研究は, これらの堆積物 を建設用材として利用するための力学的な研究などの方向 に向っていた。しかし，80 年代には世界の金探査の動向が, 既に鉱業的価值がないとされた鉱床の再評価が始まり，ブ ルガリアにおいても重鉱物の採取に伴う金の回収の可能性 が再検討され始めた。本報告に述べる大部分の金製出土品 は，この再評価過程で発見されたものである。

\section{II. 金製品の発見およびその特徵}

1. 試料採集および処理方法

最初の出土品は Kraishte 地域 (西ブルガリア, Pastuh 村

(平成 12 年 2 月 22 日受付，平成 12 年 3 月 25 日受理)

* ブルガリア科学アカデミー 鉱物学および結晶学中央研究所

* Central Laboratory of Mineralogy and Crystallography, Bulgarian Academy of Sciences, 92 Rakovski Str., 1000 Sofia, Bulgaria

E-mail: mincryst @ bgcict.acad.bg 
の北部) の Struma 川の現世沖積堆積物 (Q5) から回収し た濃集物の中に見出された (Tsintsov, 1992)。その鉱床は溝 型の河川堆積物で 70-75\%の細粒から中粒の砂からなり, その他にシルトおよび粘土と 80-100 mm 径の礫を含む。こ の沖積鉱床のサンプリングは，先ず重鉱物等を採取するた め, 特別に作った水路によって行った (Tsintsov, 1994)。こ れにより，特に多い場合には数千立方メートルに及ぶ膨大 な堆積物を効率よく処理することが出来た。得られた濃集 物は, さらに手作業の「椀掛け法」により 15-20 リットル まで濃集し, 次に, 実験室で, +2.5 mm, 2.5-1.0 mm, - 1.0 $\mathrm{mm}$ の各粒径試料にふるい分けし, 磁選機により非磁性成 分のみを分離した。この試料中の物質は，双眼実体顕微鏡 により表面組織, 金属表面の色により純度などを観察し た。研究の最初の段階では研磨片を作り, 金属の純度や元 素分布の研究に供した。EDAX9100を装備した SEM (Phillips-515) およびEPMAによる分析も行った (Tsintsov and Damyanov, 1994)。

\section{2.「白い金」としてのアマルガム}

西部ブルガリアの沖積堆積物の興味深い点の 1 つは “白い金 (white gold)”の存在である (Petrovskaya, 1973)。 Konstantinov (1949) によると, 古代の鉱山師は, これらの

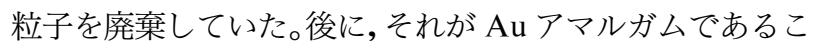
とが分かってからは, 彼らの一部はそれを採取し始めた
(Petrovskaya, 1973)。彼らは，「加熱すると溶けて白い皮が 残るので, それを取り除く」というような方法で, 不適当 な粒子を除去していた。同時代の鉱山師には，この“白い 金”について否定的な者もいた。これら鉱床地带の漂砂鉱 床の金は，より以前には主としてアマルガム法で回収され ていた (Koniyanov, 1953; Velkov, 1972)。この結果, 河川 の砂が水銀で污染され, 金アマルガムの一部がこの地域全 体に残った。“白い金”の鉱物学的性質が解明されるまで, このアマルガムの存在が採掘や金属製錬を妨げたというわ けではなかったようである。

\section{3. 金製品の特徵と存在場所}

発見された金製品は小さなワッシャー (座金) 状の小環 (ringlet), 外形 1.8-3.2 mm で平均の厚さ $0.8 \mathrm{~mm}$ の円盤状で ある (Fig. 1a, d; Fig. 3e)。双眼実体顕微鏡で調べると, 個久 の小さな金製品のかけら，および，極めて少量だが，ほぼ 直径 0.01-0.13 mmの「金製の球」が見つかる (Fig. 1a， d; Fig. 2d)。これらの製品の分布を研究する目的で,さらに, こ の上流 130 から $150 \mathrm{~m}$ 離れた溝状の鉱床の新しいサンプル を採取し調べた。そこでも最初の場所と同様の多くの金製 品が見つかり, その球の直径は最大 $0.3 \mathrm{~mm}$ に達する。最初 の発見地から $1.6 \sim 1.8 \mathrm{~km}$ 上流地点でもサンプリングを 行ったが, 考古学的な対象物は, 全く発見できなかった。こ れらの調査の結果から，主として粗粒の破砕物の未分化な
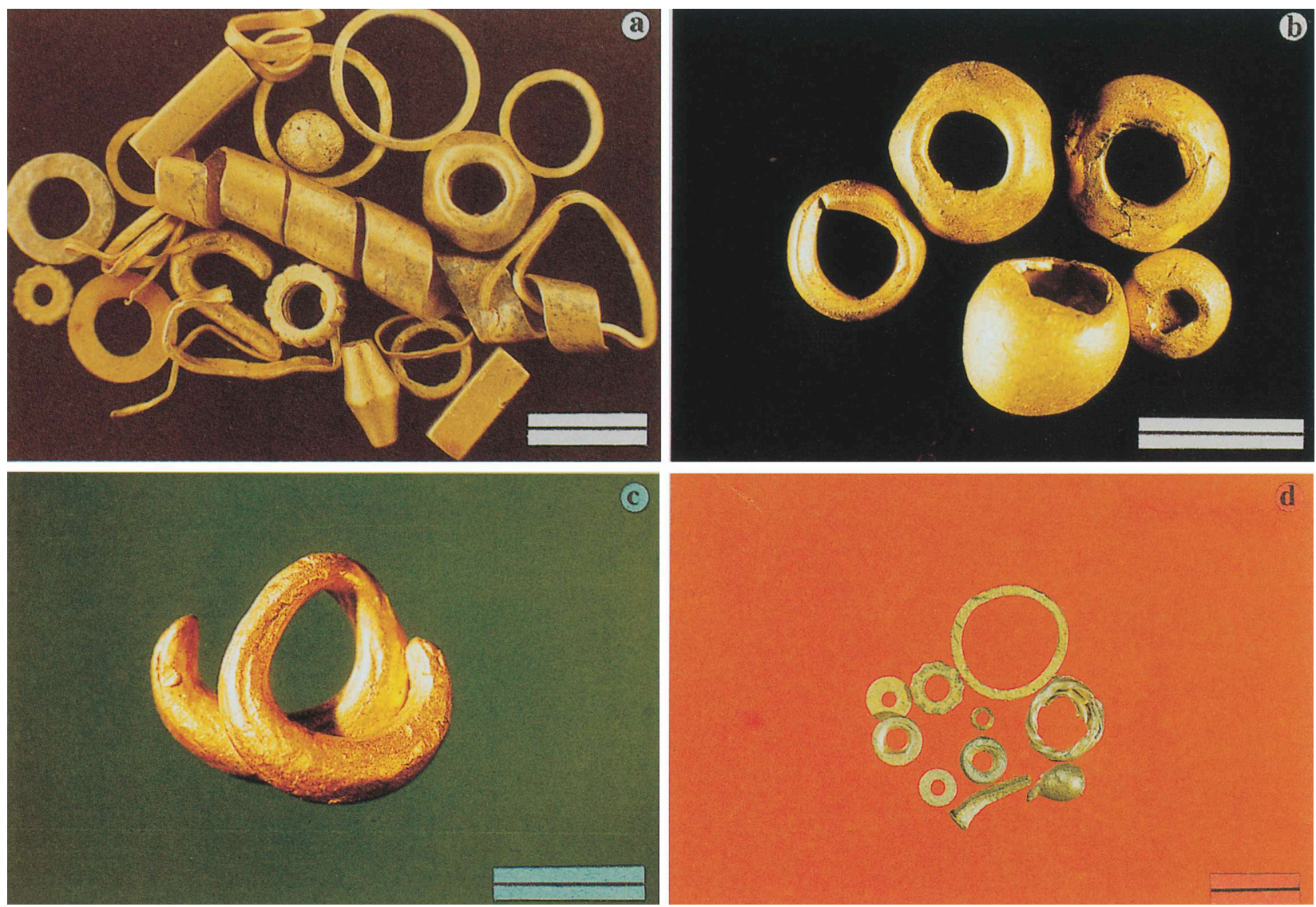

Fig. 1. Golden articles from SW Bulgaria. Scale bar length in each photograph indicates $5 \mathrm{~mm}$. 
堆積物を探索すべきであるとの指針を得た。このような破 砕堆積物は, 最初の発見地点から約 $600 \sim 700 \mathrm{~m}$ の範囲で谷 を満たしていた。多くのワッシャー状のものに加えて，ら せん状に巻かれた純粋な金製のリボンが見つかった。この らせん状のものが見出された地点から 20-25 m 離れて, 色々な大きさの金のビーズも見つかっている。これらに 伴って, 最大径 1.8-2.0 mm に達する比較的大きな金製の球 も見つかった。

15 年間に渡る探査により, 西ブルガリアの沖積鉱床地域 は，金の採取と製品の製造のために開発されていたことが
明らかになった。この地域では，5000を超す製品が，12 個 の互いに独立な鉱床から見つかった。金製品を肧胎する河 川堆積物が発見されたのは次の河川である: Struma川, Ogosta 川, Iskar 川, Palakaria 川, Kopriven 川, German 川, Dragovishtitsa 川, Uineshtitsa 川, Topolitsa 川, Zlatitsa 川, 等。金以外の金属製品, 即ち, 銀製のワイヤ, “ローマ・ブ ロンズ”のコインも極めて希であるが，Kraishte 地域から 見つかっている。南西ブルガリア (Struma川, Palakaria 川, Dragovishtitsa 川, German 川, Kopriven 川, Uineshtitsa 川，その他) と北西ブルガリア (Ogosta川, Zlatitsa 川) の
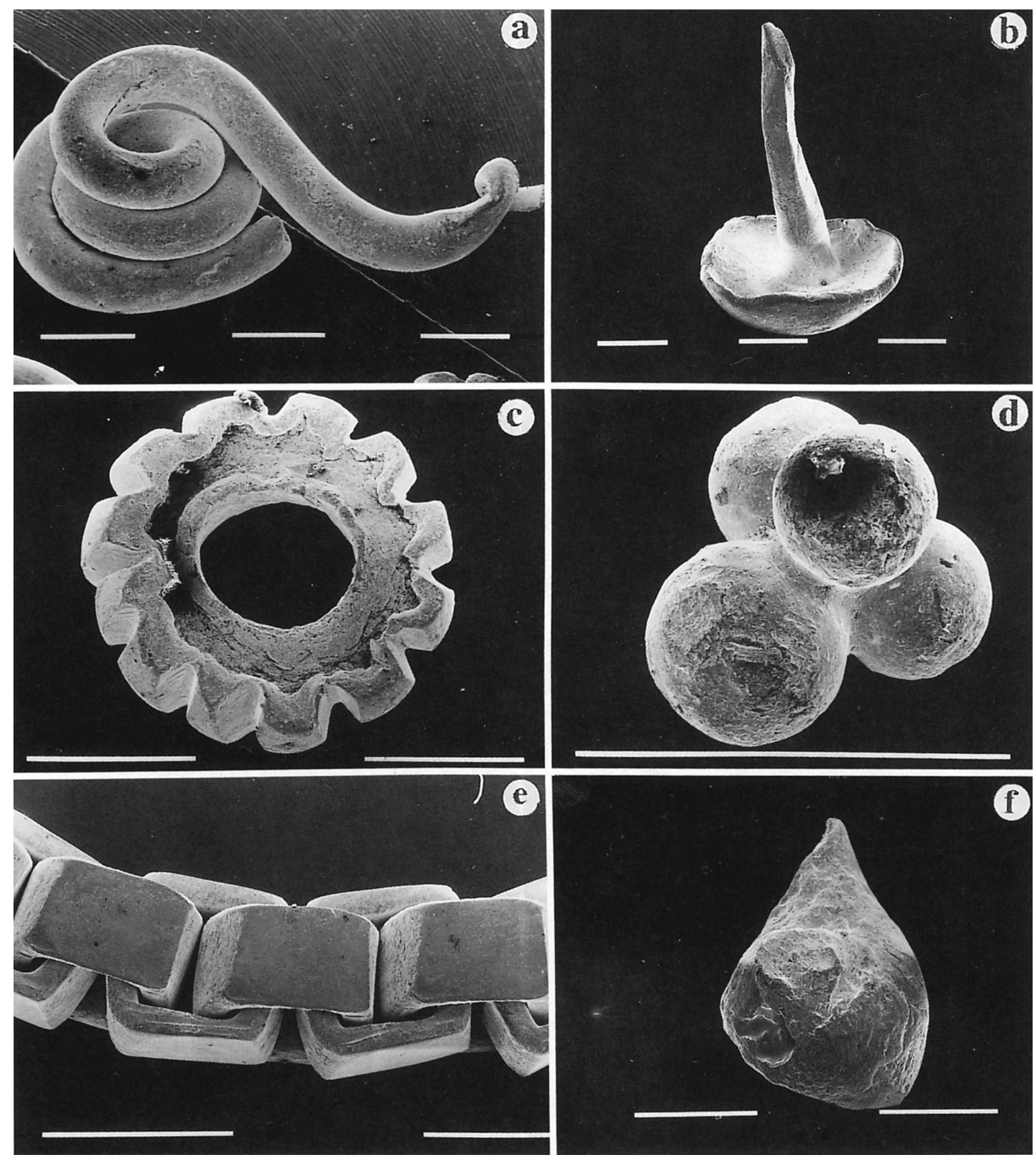

Fig. 2. SEM photographs of golden articles from some areas in SW Bulgaria; (a), (c), (d) and (e) from Kotsherinovo; (b) from Ruzhdavitsa; (f) from Tshetirtsi. Bar length is equal to $1 \mathrm{~mm}$ in each photograph. 
出土品の間の形態的および発見状況の差異が明らかに認め られている。

\section{4. 南西ブルガリア出土の金製品}

南西ブルカリアの金製品は平たいワッシャー状小環，柱 状ビーズ，両錘型ビーズ，板，らせんリボン，中空柱，〈 ぎ，その他 (Fig. 1, 3,4) である。平たいワッシャー状小環 と, 柱状ビーズの大きさ $1 \mathrm{~mm}$ から $12 \mathrm{~mm}$, のものが卓越 している。最大のものは, らせん状リボンで, 長さ $21 \mathrm{~mm}$ に達する。何百万もの小さな金球は, いずれの場所からも 発見される。それらの大部分は, 球状で, 希に液滴状 (Fig. 2f) をなし, 径は $6 \mu \mathrm{m}$ から $3 \mathrm{~mm}$ である。これらの金製出 土品の共通点は純粋に装飾的で細密な加工がなされている ことである。それらの表面は黄金色, 僅かに曇った金色, 希 に物理的に沈殿物が付着し, 暗赤色水酸化鉄により殼状に 被覆されている。幾つかの製品の SEM 表面観察によると, 金表面の再結晶による多層構造が存在している。水銀を含 みアマルガム化している場合には，まるで鉄を含んだ物質 のようにみえるが，アルコールランプで加熱すると，再び 金色となる。局部的な表面分析によると，それらは大部分 は，85\% 以上の高い金純度で，内部も同じ程度の純度であ る。EPMA 分析によると, 不純物は銀 $(\sim 15 \%)$ および銅 ( 2.0\%) であり, 比較的均質に分布している。この事は, 製 品が鋳造されたことを暗示する。変形したものもあるが, これらは河川堆積過程における機械的作用の結果である。 漂砂鉱床中の分布, 機械的摩滅の程度などの性質に関して は，これらの考古学的対象は，沖積鉱床中の天然起源の金 粒のものと似ている。より小さな製品 (小環やピアス状円 板) では，大きなもの (ビーズ，および，らせん状リボン)
より良く原型が保存されている。これらのことは偶然では なく, より小さな金粒は活発に発達する漂砂鉱床内部に深 く沈み周囲の硬い鉱物による摩耗から守られたからであ る。

Petrovskaya (1973) によると, 金の再結晶は, 表層条件下 では，主として銀の溶脱過程で生じ，結果として，表層の 金純度が増す。出土品のある種の物の表層では，この過程 を暗示するように金の純度が増している。さらに，幾つか の表層の結晶化組織では，これらが，その後の鉱山開発や， 堆積作用にもかかわらず，あまり運搬作用を受けていない 事を示している。

金粒の大きさと，流れによって運搬された距離との直接 的な相関性から，多くの研究者は，自然金粒を含む多くの 漂砂鉱床は，金を含む母岩の直近にあるとしている。従つ て，金製品を含む現在の Kraishte 沖積層を供給した考古学 的地点も, 相対的に大型の出土品が見つけられた場所のご く近くであると推定される。

\section{5. 北西ブルガリアの金製品}

北西ブルガリアの金出土品は，南西ブルガリアのものよ り多様な形態を持っている。それらは，平板ワッシャー型 小環，柱状および両錘状ビーズ，輪状または異なった形に 平らに成形された針金，板，イアリングの一部 (?), 釘等 である (Fig. 2)。それらの内の幾つかは, 堆積途中の圧迫に より強く変形しているが, 表面の研磨組織の痕跡は残って いる。アマルガム，または，鉄水酸化物で污染されている 様子はない。金純度は $65.0 \% て ゙ ，$ 他の成分は銀のみである。 球状金粒は南西ブルガリア産の場合よりも極めて少ない が，その径は $5.0 \mathrm{~mm}$ に達する。平板ワッシャー状小環およ
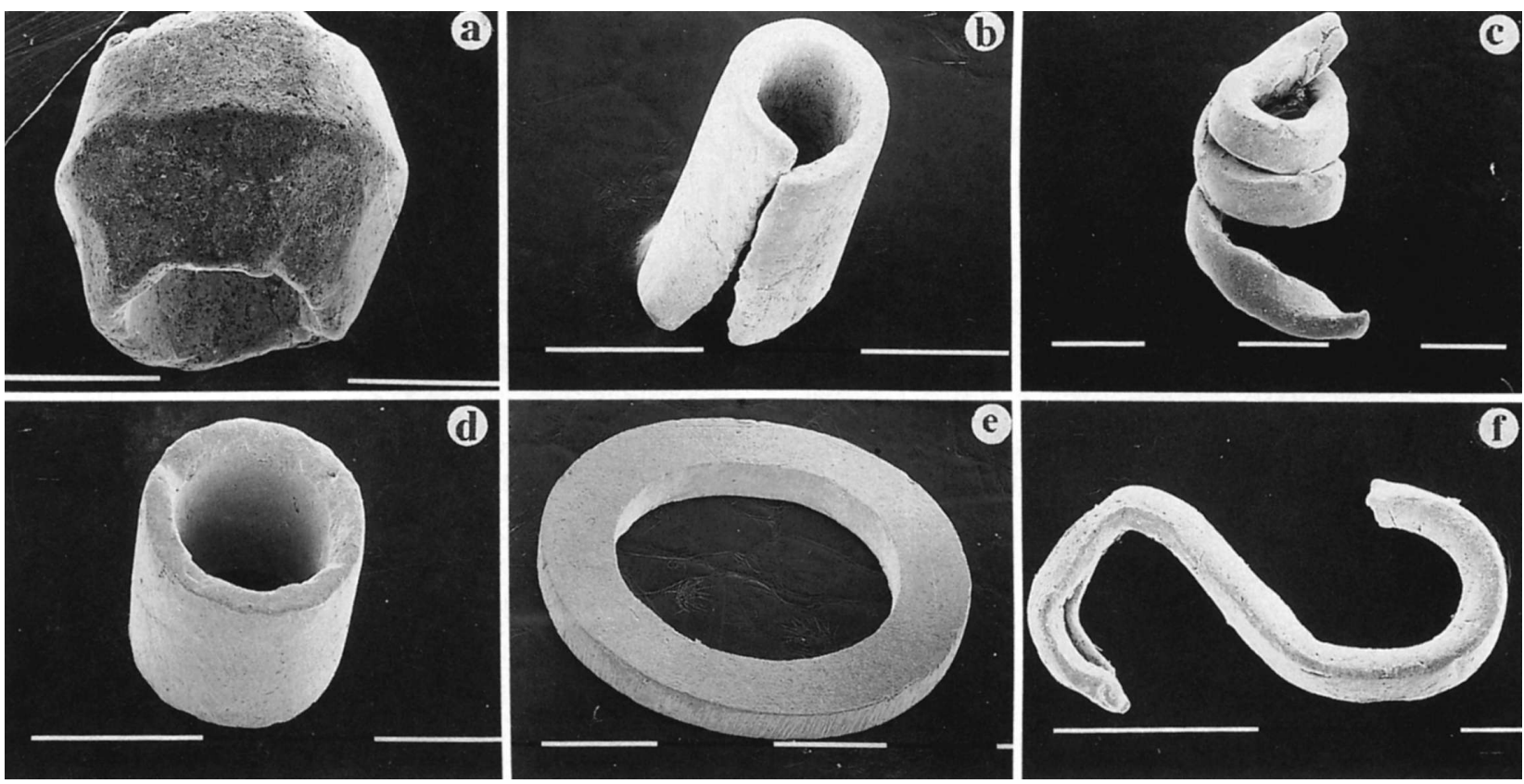

Fig. 3. SEM photographs of golden articles from some areas in SW Bulgaria; (a) from Kotsherinovo; (b) and (d) from Gorno Uino; (c) from Tshetirtsi; (e) from Pastuh; (f) from Ruzhdavitsa. Bar length is equal to $1 \mathrm{~mm}$ in each photographs. 

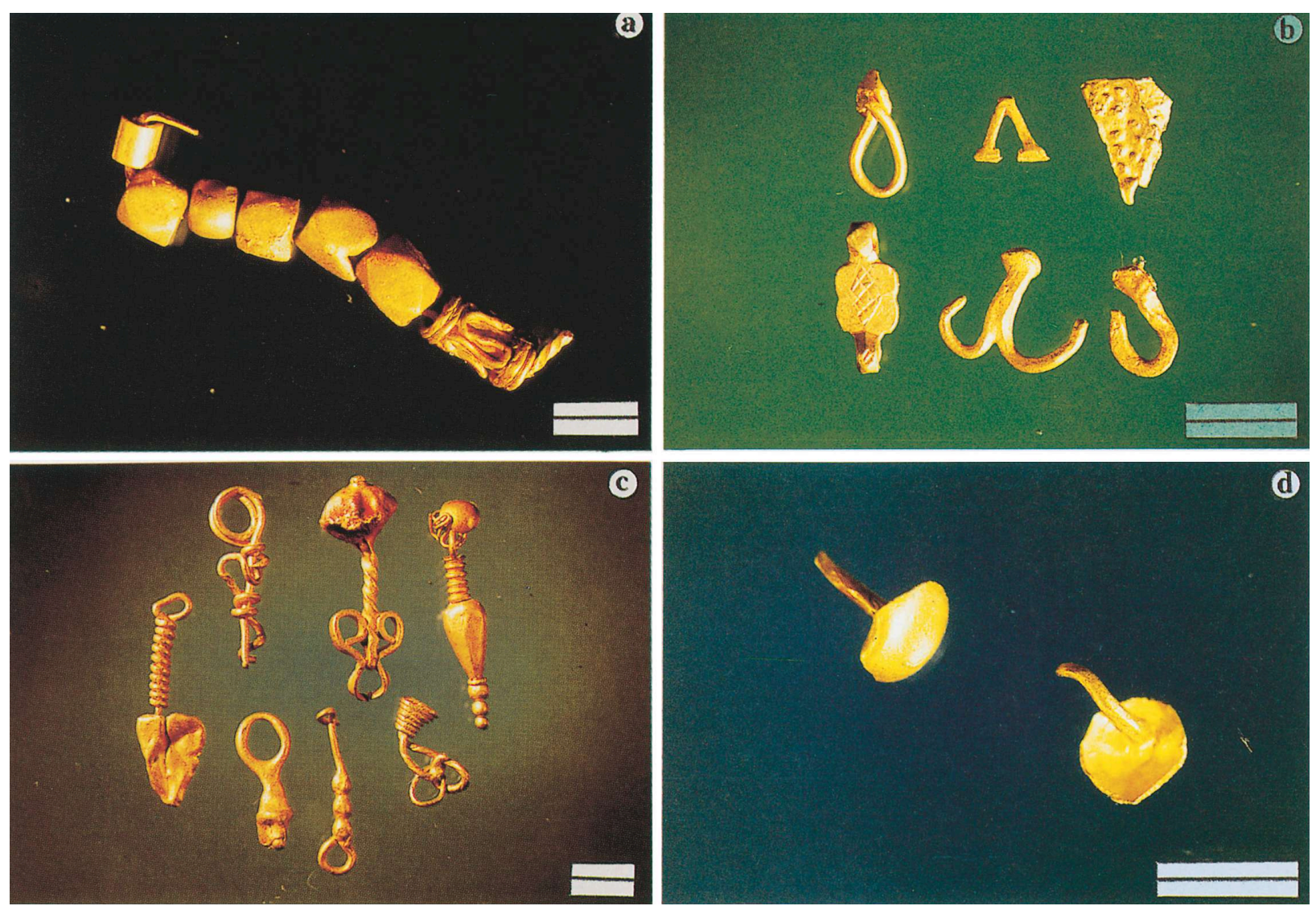

Fig. 4. Golden articles from NW Bulgaria. Scale bar length indicates $5 \mathrm{~mm}$ in each photograph.

び柱状ビーズが主で，希にらせん状リボンも見つかってい る。

\section{III. ブルガリア古代金製品の起源と変遷}

この沖積堆積物中の金製品の存在は，恐らく，その上に 古代の集落の存在した台地が河川により侵食される過程で 成立したものであろう。この考古学的サイトの詳細を明ら かにすることは困難であるが，膨大な量の小さな球状金粒 が見つかることから，集落には古代の金の製錬工房が存在 していたことが推測される。Pernicka (1994) によれば，金 鋳造の大部分の技術的基盤は, 紀元前 5000 年末には完成の 域に達し, 紀元前 5100 年には現在の西ブルガリアのこの地 域の金採掘現場のすぐ近くに，金の製錬と加工の工房が存 在していた (Pernicka, 1994)。工房群は通常鉱床の近くに存 在するが，例外もあるので，これら位置関係を分析的に追 求すべきである。例えば, 鉛のアイソトープ分析 (Brill and Wampler, 1965) により, 考古学的出土品とその原料を供給 した鉱床の金とを比較することによって明らかにされよう (Pernicka, 1994)。この場合, 出土品の破損を最小限に抑え, かつ精密な分析が望まれることは勿論である。

バルカン半島へのドリア族の侵入時 (起源前 1000 年) には，かなりの民族的変化が起きた (Velkov，1972)。それ によって，当時の文明の精神的および物質的中心地域が略
奪・破壊された。金工房も同時に破壊され，地上の痕跡は， その後の自然の作用により完全に覆われ，以後の歴史的情 報の欠如につながった。

1972 年銅石器時代とされるブルガリア東部の Varna の 共同墓地が発見されたが，これは，この国の他のいかなる 発見とも異質なものであった。それは紀元前 4000 年末のも のと同定され，その当時ブルガリアで金と銅の採掘と製錬 が行われていたと推測された。しかし, 研究者の一部は, 出 土した「財宝」は，ブルガリアで製造されたものではない と考えていた。その論拠は, Varna 古代墳墓の金製品の幾つ かには，白金が含まれており，これは従来のブルガリアの 金には見出されていなかったからである (Hartmann, 1978)。後に, Weisgerber and Pernicka (1995) は金の中に 白金族の不順物が存在することを見つけた (Weisgerber and Pernika, 1995)。重鉱物の研究者達は，南西ブルガリア の堆積物からの濃集物中に白金族鉱物の小粒が，少量含ま れることを示した (Tsintsov and Damyanov, 1994; Tsintsov, 1998)。そのような白金属鉱物は，金と共に，過去にも 見出されており，一般に (前述のアマルガムと共に)「白い 金 (white gold)」として知られていた。砒白金鉱 (sperrylite, $\mathrm{PtAs}_{2}$ ) は最も多く見出される鉱物である (Tsintsov and Damyanov, 1994)。恐らく古代の鉱山師は，これらの粒子を 金の溶融の前に取り除くことが出来なかった。南西ブルガ 
リアの漂砂鉱床産の金の化学分析から，幾つかの白金属元 素 (PGE) の不純物を見出した，それらは，白金 (10-30 ppm) およびオスミウム (1-3 ppm) である (Tsintsov未発 表データ)。これらの事実から, ブルガリアで採掘され, 製 錬された古代の漂砂鉱床産の金は一定量のPGE を含むこ とが明らかにされた。

\section{IV. おわりに}

西部ブルガリアの沖積層中の「財宝」は，この地域が，金 の採取と製錬の中心であったことを示している。Varna 銅 石器時代墳墓に地理的に近く, 出土品の類似性も高いこと から，両者の関係が極めて密接であることがうかがわれる (Tsintsov, 1992)。これらの沖積層出土品の特徴はVarnaの 出土品の時代が物語る長い時間と同一時代であることを示 している。当時の交流が事実であれば，その接点はどこに あったのか？ それが単に金であるというばかりでなく， 人類が製錬した最古の金製品 (Varna 墳墓) であるからこ そ,それを探ることに意義がある。この沖積層出土品は, 現 在まで, ごく僅かの専門家にしか知られていない。ともあ れ, その魅力・神秘性は考古学者の注目を喚起したばかり でなく, 関連した科学の領域にも興味を引き起こさずには おかないものである。これらの出土品は, 当時どのように 使われ，それらを作るためにどのような技術が用いられた か，特にそれが 1-2 mm と極めて小さいことは何を示すの か, 出土品と漂砂鉱床の金との関係, 水銀の起源とその機 能は何か，というようなテーマが解明されなければならな い。これらの解明により, ブルガリアの地に存在し, かつ 物質文明がこの様に発達し完成の域に到達していた古代文 明をより良く理解するのに役立つであろう。また，恐らく Varna 墳墓遺跡に関しても, より重要な情報を提供するで あろう。このような見通しを踏まえて, 試料が収集された が, 分析的な研究をさらに進め, その結果の説明を行うと いう, 最も困難な研究が残っている。

\section{引用文献}

Brill, K. and Wampler, J. (1965): Isotope ratios in archaeological objects of lead. In Application of science in the examination of works of art (Young Ed.), Boston, 155166.

Hartmann, A. (1978): Ergebnisse der spektralanalytischen Untersuchung aneolithischer Goldfunde aus Bulgarien. -Studia Praehistorica 1-2; 27-45.

Konstantinov, M. (1949): Old native gold mining in Kraiste. Minno Delo, 4, 81-84.

Konyanov, G. (1953): Contribution to Mining and Metallurgy History in Bulgaria. BAS, Sofia, 160.

Marfunin, A. (1987): History of Gold. Nauka, Moskow, 246.

Pernicka, E. (1994): Status of Natural Science Studies on the Most Ancient Metals. In Problems of the Earliest Metallurgy (Todorova, H., Popov, P. Eds), MGU, Sofia, 14-89.

Petrovskaya, N. (1973): Native Gold. Nauka, Moskow, 348.

Tsintsov, Z. (1992): Unique finds of golden articles in alluvial placers. C. R. Acad Bulg. Sci., 45[6], 59-61.

Tsintsov, Z. (1994): Sampling of sediments for minerals belonging to the platinum-group. Minno Delo 1 Geologia, 11, 32-35.

Tsintsov, Z. (1998): Composition, distribution and transportation of platinum-group minerals in alluvial sediments of Blagoevgrad graben. Review of the Bulgarian Geological Society, 59[2], 59-65.

Tsintsov, Z. and Damyanov, Z. (1994): Sperrylite from Struma River alluvial placers, Blagoevgrad graben, SW Bulgaria. N. Jb. Miner. Mh., H11, 518-528.

Velkov, V. (1972): Ore Mining in Ancient Thrace. Annual of the National Polithechbic Museum, 2, 23-38.

Weisgerber, G. and Pernicka, E. (1995): Ore mining in Prehistoric Europe, an overview. In Prehistoric Gold in Europe(Morteani, G. and Northover, J. Eds.), 159-182, Proceedings of the NATO Advanced Research Workshop on Prehistoric Gold in Europe, Seeon Germany, September 27-October 1, 1993.

(溝田＼cjkstart忠人 訳)

\section{補 足 解 説}

\section{Supplemental remarks}

\section{溝田＼cjkstart忠人 (Tadao MIZOTA)*}

1972 年ブルガリアの東部, 黒海沿岸に近いVarna 市近郊 から, 紀元前 4000 年頃と思われる墳墓の遺跡が発見され, 世界最古の黄金文明として脚光を浴びた。既に 1982 年日本 では, この遺跡の出土品の展示会が, 東京 (新宿, 池袋), 岡 山, 山口, 仙台, 大阪の各地で開催されている。訳者は, た
またま山口会場の入場者の第 1 号となり，この展示会用に 日本テレビ放送網文化事業団から発行された写真集 (江上 奈波夫他, 1982) を贈呈され,そのことが翌日の新聞に載る という珍事に巻き込まれ，以来，学生時代には当然習って いなかったブルガリアのこの古い文明が心に残っていた。

* 山口大学工学部機能材料工学科, $=755-8611$ 宇部市常盤台 2-16-1

* Faculty of Engineering, Yamaguchi University, 2-16-1 Tokiwadai, Ube 755-8611, Japan E-mail: mizochue@ po.cc.yamaguchi-u.ac.jp 